\title{
Early childhood care and education educators' understanding of the use of music-based pedagogies to teach communication skills
}

\begin{tabular}{|c|c|}
\hline \multicolumn{2}{|c|}{$\begin{array}{l}\text { Authors: } \\
\text { Deborah A. Arasomwan }{ }^{1} \text { (D) } \\
\text { Nontokozo J. Mashiy }{ }^{2}\end{array}$} \\
\hline \multicolumn{2}{|c|}{$\begin{array}{l}\text { Affiliations: } \\
{ }^{1} \text { Discipline of Early Childhood } \\
\text { Education, School of } \\
\text { Education, University of } \\
\text { KwaZulu-Natal, Pinetown, } \\
\text { South Africa }\end{array}$} \\
\hline \multicolumn{2}{|c|}{$\begin{array}{l}{ }^{2} \text { Discipline of Early Childhood } \\
\text { Education, Faculty of } \\
\text { Education, University of } \\
\text { Zululand, Empangeni, } \\
\text { South Africa }\end{array}$} \\
\hline \multicolumn{2}{|c|}{$\begin{array}{l}\text { Corresponding author: } \\
\text { Deborah Arasomwan, } \\
\text { deborahavosuahi@gmail. } \\
\text { com }\end{array}$} \\
\hline \multicolumn{2}{|c|}{$\begin{array}{l}\text { Dates: } \\
\text { Received: } 19 \text { June } 2020 \\
\text { Accepted: } 12 \text { May } 2021 \\
\text { Published: } 20 \text { Aug. } 2021\end{array}$} \\
\hline \multicolumn{2}{|c|}{$\begin{array}{l}\text { How to cite this article: } \\
\text { Arasomwan, D.A. \& Mashiy, } \\
\text { N.J., 2021, 'Early childhood } \\
\text { care and education } \\
\text { educators' understanding of } \\
\text { the use of music-based } \\
\text { pedagogies to teach } \\
\text { communication skills', South } \\
\text { African Journal of Childhood } \\
\text { Education } 11(1) \text {, a896. } \\
\text { https://doi.org/10.4102/ } \\
\text { sajce.v11i1.896 }\end{array}$} \\
\hline \multicolumn{2}{|c|}{$\begin{array}{l}\text { Copyright: } \\
\text { (c) 2021. The Authors. } \\
\text { Licensee: AOSIS. This } \\
\text { is licensed under the } \\
\text { Creative Commons } \\
\text { Attribution License. }\end{array}$} \\
\hline \multicolumn{2}{|l|}{ Read online: } \\
\hline 回要回 & $\begin{array}{l}\text { Scan this QR } \\
\text { code with your } \\
\text { smart phone or } \\
\text { mobile device } \\
\text { to read online. }\end{array}$ \\
\hline
\end{tabular}

Background: Early Childhood Care and Education (ECCE) learners have unique needs, and specific pedagogies, therefore, need to be employed to support the acquisition of their essential skills. A great deal of research has been conducted on the use of music-based pedagogies to teach mathematics, life skills, civics and literacy at various levels of education. In South Africa, where ECCE is a relatively new educational sector, very little structure has been put in place to facilitate using music-based pedagogies to teach communication skills to ECCE learners.

Aim: The aim of this study was to explore ECCE educators use music-based pedagogies to positively impact children's communication skills and language development.

Setting: The qualitative case study was conducted at two Urban ECCE centers in Durban, KwaZulu Natal Province, South African.

Method: The study was informed by a social constructivist paradigm underpinned by Vygotsky's sociocultural theory, focussing on ECCE learners' interaction with the more knowledgeable other (MKO). Data were generated through semi-structured interviews and classroom observations with six educators, and through document analysis. The data were analysed using thematic analysis.

Findings: The study confirmed that the ECCE educators have some levels of understanding of using music-based pedagogies as a strategy for teaching communication skills to children aged from three to four, but there are constraints. These limitations include insufficient training, a lack of musical resources and the non-inclusion of music-based pedagogies in both the pre-service teachers' curriculum and the ECCE curriculum.

Conclusions: The study recommended a comprehensive review of the content and implementation of the ECCE curriculum in relation to music pedagogy.

Keywords: early childhood care and education; urban setting; songs; music-based pedagogy; communication skills.

\section{Introduction}

One of the key requirements for sustainable early childhood development is effective educators who understand developmentally appropriate practices and are able to employ diverse strategies to transfer skills to children (Knight \& Rabon 2017). Cummings (2017) confirmed that educators' understanding of appropriate teaching strategies is the determining factor for efficient and quality early childhood education. Adams-Ojugbele and Moletsane (2019) found that when children in the classroom are from diverse socio-economic backgrounds, the key indicator of a proficient educator is the ability to employ child-centred strategies for an inclusive classroom. According to Horng et al. (2005), creative Early Childhood Care and Education (ECCE) educators use a constructivist approach to learning, are able to create music and rhymes, use games, use technology and multimedia, use stories and establish a connection between the teaching content and real life.

Early Childhood Care and Education educators in developing countries need to be skilled and creative, as research has shown that many children below age five are from disadvantaged socioeconomic backgrounds and are faced with challenges that affect their readiness for further learning, such as malnutrition and generally poor health as a result of an unhealthy environment, inadequate parental care and stunted growth (Walker et al. 2011). Hence, there is a need for professional educators with the knowledge of a variety of child-centred pedagogies to transfer the necessary skills to these children. The authors further posited that the nature and characteristics 
of young children, and their way of learning, differ drastically from youth and adults, and that young children need educators with an understanding of the appropriate teaching strategies. According to Knight and Rabon (2017), studying young children through a developmental lens helps educators to understand their needs and how they might best help them to learn effectively, as ECCE learners lack the ability to communicate eloquently. Halberda and Feigenson (2008) found that children aged between three and four often experience intense emotion and are easily bored. Thus, current research advocates a shift from traditional rote teaching to employing a variety of pedagogies to support learners to construct their own learning and to develop language skills (Dalton, Mckenzie \& Kahonde 2012).

Ford et al. (2020) described language development as a process by which children acquire and understand some basic communication skills. Additionally, language development is an important milestone in early childhood that is vital for:

$[B]$ uilding a strong sense of well-being, for building a strong sense of identity and belonging and for exploring and making meaning of mathematics, the creative processes and a knowledge and understanding of the world. (Department of Basic Education [DBE] 2015:40)

The document further advises adults to speak, sing, read to and listen to young children to support them as they learn to speak and listen, and later to read and write. It is on this basis that researchers suggested that music should be employed as one of the implementation strategies to communicate with ECCE learners to aid their language development (Niland \& Holland 2019).

Additionally, Niland (2009) suggested using musical and dramatic play, sound and a variety of rhymes as a way of teaching skills to ECCE learners, including communication skills, as young children learn quickly and easily through the medium of music. Wolfe and Flewitt (2010) also advocated using a variety of communication means - including dance, pictures, videos, rhymes and musical games - to support children to develop communication competency at an early age. In addition, Herrera et al. (2014) found that using musicbased pedagogies in the classroom have a positive impact, not only on children's language development but also on their total development. Hence, it has become imperative for ECCE educators to equip themselves with these skills and to be able to teach in creative ways.

\section{Literature review}

\section{Conceptualising early childhood care and education}

Early years' education forms the building blocks and the basis for creativity, health and cognitive, emotional and social well-being, and the early acquisition of language and communication skills gives children the foundation to explore the world and new ideas (Adams-Ojugbele \&
Moletsane 2019). The United Nations International Children's Emergency Fund (UNICEF) (2014) stated that:

[E]arly childhood is a critical stage of development that forms the foundation for children's future well-being and learning and is also the key to a full and productive life for a child as well as to the progress of a nation. (p. 1)

Britto et al. (2017) found that the provision of adequate early years' education aids children's brain development and assists with the development of language, mental skills and socio-emotional aptitudes. The authors further emphasised that the provision of quality ECCE lays a strong foundation for lifetime benefits, such as educational success and social responsibility. Britto et al. (2017) confirmed that children exposed to high quality ECCE are better at exhibiting socially acceptable norms and values and are emotionally stable. Education is, therefore, an important tool for early childhood development, and the provision of rich ECCE services enhances and positively influences children's academic performance in later years (Vandenbroeck \& Lazzari 2014).

\section{Music-based pedagogy to teach communication skills to early childhood care and education children}

Roberts et al. (2014) conducted a single-subject, multiplebaseline study in the United States to explore the effects of effective teaching strategies on ECCE learners' language learning. The authors reported that the effective use of developmentally appropriate teaching strategies in the classroom had a positive impact on children's language and communication skills. Roberts et al. (2014) also found that employing constructive teaching methods with young learners at an early age was crucial for avoiding long-term, communication-related problems. Adams-Ojugbele and Moletsane (2019) found that developmentally appropriate teaching strategies are closely linked to the educator's ability to organise skills in the classroom and create an exciting atmosphere for learning.

The use of music-based pedagogies has been shown to enhance learning and to create a constructive classroom atmosphere (Eerola \& Eerola 2014). A study conducted by Britto et al. (2017) affirmed that the application of developmentally appropriate implementation strategies, such as the use of songs and rhymes in the ECCE classroom, is an important factor for achieving sustainable early childhood development. Several research studies have also established that using music to teach any skill helps learners to gain a quick understanding, makes the classroom atmosphere a positive environment for learning and promotes social interaction amongst learners, thereby aiding the growth and development of the ECCE learners (Ba'th \& Mychailyszyn 2017; Hawkins 2016; Knight \& Rabon 2017; Van Vuuren \& Eurika 2018). In addition to listening, reading and writing skills, skills in other subjects such as mathematics and life skills can be unpacked using music as a teaching strategy for other grades (Cloete \& Delport 2015; Van Vuuren \& Van Niekerk 2015). 
Khaghaninejad, Motlagh and Chamacham (2016) found that music and communication share certain characteristics, and that using music-based pedagogies for teaching, reading and listening skills to ECCE learners is therefore appropriate. For many people across the globe, music is an important part of everyday life. In addition to its cultural importance, many studies have found that music plays a key role in early language acquisition and can help boost language learning (Khaghaninejad et al. 2016; Linnavalli et al. 2018). Both language and music are represented with symbols (Hansen, Bernstorf \& Stuber 2014). In addition, neurologists have discovered that the left-hemisphere frontal lobe of the brain plays a central role in the comprehension and creation of both language and music (Jäncke 2012). Brandt, Gebrian and Slevc (2012) found that because both spoken language and music are made up of tone, melody, rhythm and tempo, when educators employ music to teach ECCE learners, communication skills become easy to learn. The authors further reported that music assists Foundation Phase learners in developing their perceptual skills, which affect language learning and which subsequently affect literacy. They, therefore, suggest using music as a strategy to teach language and communication (reading and listening) skills to these learners.

A number of other researchers have found that introducing music literacy to children in the early years enhances good speech development, and early acquisition of emotional and social skills (Cloete \& Delport 2015; Young 2016). McIntire (2007:44) concluded that 'musical rhymes and literacy go hand in hand' and are therefore a good tool for teaching communication skills to ECCE learners. Nel et al. (2016) exploratory research on literacy teaching and learning at Grade R level in selected South African schools reported that the acquisition of literacy and communication skills by ECCE learners is below the expected standard, especially for children in rural settings. The authors identified pedagogical barriers and socio-economic challenges as the major reasons for this. A number of studies on the use of music in the ECCE classroom have confirmed that using music as part of a teaching strategy helps to address some of these problems (Cloete \& Delport 2015; Eerola \& Eerola 2014). Significantly, recent studies have affirmed that the use of music, rhymes, dramatic play with musical accompaniment and musical play in the classroom has a strong positive influence on underprivileged and at-risk children's acquisition of important skills, including language and communication skills (Hancock \& Wright 2018; Haslip \& Gullo 2018). These authors note that these are effective teaching strategies that align with and are appropriate to children's development. In addition, South Africa's National Curriculum Framework (NCF) guidelines suggest employing music to teach 'different sounds and words', 'sound games', 'rhythm and pitch' and 'songs and rhymes', in order to make learning more appealing to ECCE learners and to build their communication skills (DBE 2015:42-43).

\section{Early childhood care and education educators' understanding of music-based pedagogy to teach communication skills}

Nearly, all South African universities offer creative arts training in their pre-service teacher education programmes; the subject is usually taught in a single semester and music is only one component of creative arts, but pre-service teachers are given basic knowledge of the use of music in the classroom (Van Vuuren \& Eurika 2018). De Vries (2013) reported that some developed countries give their specialist educators music training, and allocate musical teaching resources and funding to aid their use of music as pedagogical medium. Gillespie and Glider (2010) explored pre-school educators' use of music to support children's learning, and conducted classroom observations to establish ECCE educators' understanding of using music to teach learners. Their findings showed that all the educators understood music and used it frequently in the classroom to scaffold children's learning. Nearly, all the ECCE educators in the study reviewed, reported using music every day, both for supporting learners' cognitive and social development and for transition from one activity to another. Ryan (2020) reported that educators employed musical activities that included singing along to compact discs (CDs) or following musical cues.

\section{The early childhood care and education educators' constraints to the use of music-based pedagogy to teach communication skills in early childhood care and education}

Implementing a variety of teaching approaches to help children learn is imperative for the ECCE classroom (Kamalodeen et al. 2017). The choice of teaching strategy can enhance or prevent effective teaching and learning. However, no method can be recommended for every context. It is necessary that ECCE educators use flexible methods that meet the needs of all the children and are suitable for different contexts (Alterator \& Deed 2013).

However, educators are faced with a range of barriers to using musical rhymes as a teaching strategy in the ECCE classroom. Whitcomb (2013) examined the challenges in teaching improvisation in elementary general music and found that a lack of musical aids, a lack of self-confidence and inadequate musical training were barriers to the effective use of music in the classroom. Mohangi et al. (2016) found that South African schools in rural areas tend to be underresourced and to lack basic infrastructure such as roads, electricity, information and communication technologies, sanitation and teaching resources. These problems are a hindrance to educators' ability to access and use musical resources. The nature of ECCE requires that educators employ a diverse range of teaching methods to support their learners' holistic development, hence the need for early childhood educators to improve their expertise on developmentally appropriate early childhood teaching practices (Bolduc \& Evrard 2017). Most countries recognise 
the role of music in the ECCE curriculum, hence its inclusion in teacher education.

However, Rule and Land (2017) found that educators' pedagogical strategies, which largely involved rote learning methods, hindered the learners' effective acquisition of reading skills. In a nutshell, most of the studies reviewed on this topic uniformly ascertain that the pedagogical strategies adopted by South African educators by and large hamper the effective learning of communication skills (Modisaotsile 2012; Sampa et al. 2018).

In addition, because ECCE is a relatively new learning phase in the South African educational sector, very little structure has been put in place to facilitate using music-based pedagogies at ECCE centres. In spite of decades of research that has found that the inclusion of the arts in early childhood education programmes has a positive and long-lasting effect on the academic and holistic development of a child, there is no strong structure for providing ECCE educators with efficient training in music (Haslip \& Gullo 2018; Parsad \& Spiegelman 2012).

The primary research question that informed this study was therefore:

- what is the ECCE educators' understanding of using music-based pedagogies as a strategy for teaching communication skills to children aged from three to four?

\section{Theoretical framework}

This study was grounded on Vygotsky's (1997) sociocultural theory (SCT) and Shulman's (1987) Pedagogical Content Knowledge (PCK). Sociocultural theory views language and communication as the means by which learners develop higher cognitive skills (Vygotsky 1997), and emphasises children's interactions with their cultural context and their environment as critical for the acquisition of any skill. The three main themes of Vygotsky's SCT are social interaction, the more knowledgeable other (MKO) and the zone of proximal development. From Vygotsky's sociocultural perspective, effective learning of language and communication skills is embedded in the constructive interaction between educators and learners, and children develop skills when an adult, such as an educator, caregiver or parent, provides reinforcement and stimulation. Vygotsky posited that the environment as a whole has a strong impact on shaping an individual, and that all the systems around the child must give support that will nurture the child's optimal development (Shabani 2016). Along with Bronfenbrenner (1992) and Piaget (1952), the MKO of Vygotsky's SCT refers to somebody who has a better understanding or more experience than the learner in relation to a task, process or concept (McLeod 2018; Shabani 2016). When the MKO scaffolds the learners' knowledge by facilitating the learners' repeated participation in a variety of activities, the learners gradually develop new knowledge and skills (Fernández et al. 2013).
The emphasis of PCK is on the teacher having sound comprehension of the subject content and the best pedagogies to comprehensively pass the content to the learners. Shulman highlights four questions to be answered by educators in their attempt to impact skills of learners:

What are the sources of the knowledge for teaching? Is the teacher well-trained? In what terms can these sources be conceptualised? Should the training on the concept be taught? What are the processes of pedagogical reasoning and action? What are the processes of passing the skills? What are the implications of teaching policies and educational reform? What is the outcome? The result must be visible. On this study, it is expected of the ECCE educators to receive some training on the concept of music. The third is on carving out the suitable way of using it as pedagogy to pass the contentcommunication skills to the ECCE learners and finally the impact on children language development.

\section{Research methodology}

In this qualitative case study, ECCE educators were interviewed and observed as the MKOs in order to ascertain how they interacted with their learners and how they scaffolded their learning of communication skills using musical pedagogies. A purposive sampling method was adopted in selecting participants based on their experience, years of teaching in ECCE and willingness to participate in the research. This was carried out after paying visits to the research centres to establish cordial relationship with the educators. Thus, the selection of the educators with needed information is necessary to provide answers to the key research questions. This sampling method is in line with Teddlie and Yu's (2007) argument on the purposive sampling method in research as they posit that it involves making decision on people, group of people or schools which have rich knowledge about the subject under research. Data were generated in three phases over 6 months. The first phase consisted of semi-structured, open-ended interviews with six ECCE educators who had 4-18 years of teaching experiences in the ECCE phase. The purpose of the interviews was to explore their understanding and knowledge of using music to teach language and communication skills, and to establish why they chose to use music as a teaching strategy. The second phase of data generation consisted of participant observation. The third phase of the data generation consisted of document analysis. Relevant documents such as lesson notes, educators' weekly working notes, policy documents, the Curriculum and Assessment Policy Statement (CAPS) document and the Dolphin school curriculum adopted by the ECCE centres were analysed in relation to the information obtained during the interviews. The research setting was two urban ECCE centres in Durban, South Africa, which were well resourced and had a good record of academic performance. The generated data were analysed thematically, using the deductive and inductive reasoning approach designed by Miles and Huberman (1994). 


\section{Ethical measures}

Bertram and Christiansen (2014) explained ethics as norms for conduct that distinguish between acceptable and unacceptable behaviour in research. Several measures and consideration were put in place to ensure that the necessary steps for this qualitative study were duly followed and adhered to. Thus, gate keeper permission was obtained from the school heads of each of the research study. I also visited the participants to establish cordial relationship and briefed them of the purpose of the research under studying.

\section{Findings}

The study engages six ECCE educators as participants from two ECCE centres which are ascribed pseudonym: Golden Kiddies and Little Angels. In this study, semi-structured interview was employed to generate direct data from the participants. Also, outside and classroom observation was carried out to watch the real-life practice of the use of music to teach language and communication skills to the children. The findings are presented and discussed under the following themes: the nature of ECCE educators' training, communication skills in the ECCE curriculum, ECCE educators' understanding of using music-based pedagogy to teach communication skills and barriers to employing music-based pedagogies in the ECCE classroom and observation exercise.

\section{Theme 1: The nature of early childhood care and education educators' training}

The researchers set the motion by asking the participants to expound on their conceptualisation of music and how they came about their knowledge and ability to use musical rhymes effectively to impact ECCE learners with Language and Communication skills. Their responses show that most of them had undergone musical training at a level of their education. Some of the participants who pass through the University of South Africa (UNISA) attested to the fact that music is part of the course that is taught in the Early Childhood department of the university.

The participants' responses revealed a connection between their training and their ability to effectively employ music as a teaching strategy to teach communication skills in the classroom. One of the participants stated that she receives musical training from her teacher college and higher institution. She declares that:

'I did music when I was in Teacher College, we are taught how to teach music and how to use music to teach other subjects, also we learned how to play musical instrument and how to make or improves some musical instruments. Music is a mandatory course across all levels of education in the country. I also did teach practice in music during my teacher training program.' (A female ECCE educator, 33 years old)

The participant below had also received adequate teacher training in music pedagogy, she described how she used musical activities to teach multiple skills:
'Music was one of the modules I did during my Early Childhood Development training at university, and when we did our teaching practice, we were required to teach music. We were taught series of rhymes and children songs for different purposes. Thus, it is not difficult for me to employ music to teach any topic, including helping them to learn how to communicate and other skills.' (A female ECCE educator, 44 years old)

Some others do not have adequate training in music but supported their musical skills with downloaded children's music from the Internet. Hear her voice:

'I had Partial training in music, I did only diploma in music which is not enough to for mebut I go through the internet to learn various music that I can use to teach learners, especially different Video on children music from the internet such as Jack Hartmann Kiddies video. I also take time to practice music at home just to gain more knowledge to give my best.' (A female ECCE educator, 37 years old)

The response of the next participants on musical training is like the above, she had a brief training in music:

'I do receive music training but not much, we did a module in music for just a semester. It is just a rudiment of music, however the knowledge received coupled with the fact that I came from a music loving family helped me to use music to teach the children with ease.' (A female ECCE educator, 40 years old)

Conversely, in the perspective of the other participants, they claimed not to have formal musical training and therefore struggled to use music as a pedagogical strategy. Below is her voice:

'I cannot use music effectively to teach communication skills. I do not have musical training and do not have a singing voice. I am struggling and get embarrassed at times. Do you now see the reason why I am struggling with how best to use music to teach? Now I spend a lot of time on trying to upgrade my skills, because I now realize the importance of music in teaching these children. Virtually all the activities are taught using music. I wish the university knew the great importance of music and would give more training to pre-service teachers.' (A female ECCE educator, 30 years old)

\section{Same with the participant below:}

'I do not have formal music training, I was a trained accountant, but God called me into establishing ECCE centre.' (A female ECCE center's principal and educator, 53 years old)

Training and expertise were, therefore, determining factors in the participants' ability to use music as pedagogy. Thus, from this educator's comment above, only two of the participants had sound formal musical training, two others have partial musical training and the remaining two do not receive musical training at all.

\section{Theme 2: Communication skills in the early childhood care and education curriculum}

This study is on the ECCE educators' understanding of using music-based pedagogy to teach communication to children. 
The analysis of the data from the two centres shows that there was no precise content for communications skills. They claimed the children are too young to learn communication skills. The participant stated that:

'We do not have specific content on communication skills because they are too young for that, but we use music for virtually all the activities and children learn quicker when you teach with music, including speech development.' (A female ECCE educator, 40 years old)

Similarly, another participant from the second centre mentioned the same thing. Hear her:

\begin{abstract}
'For children ages 3 and 4, we teach them general concepts of communication, such as teaching them how to talk in a polite way. We have some songs that impact that to them, and they could make simple polite sentences and could respond to questions from the teachers. Some of the children that are restless and does not pay attention when they came newly could now communicate well and respond to questions.' (A female ECCE center's principal and educator, 53 years old)
\end{abstract}

The data on this point show that there is no specific communication curriculum for the learners at the two centres. However, they have songs to teach basic communication skills to the children.

\section{Theme 3: Early childhood care and education educators' understanding of using music-based pedagogy to teach communication skills}

The ECCE educators gave their voices on their understanding of the use of music as a pedagogical medium to support children to learn basic skills, they backed up their points with various sources of their understanding. One of the participants who studied outside South Africa stated below that:

'I have good understanding of the importance of music to children development. We are taught this during my teacher training, and various children music such as lullaby, different rhymes were learnt. I can improvise simple music for any topic I choose to teach to children.' (A female ECCE educator, 33 years old)

Another participant ascribed her understanding of the use of music in the ECCE classroom through her engagement with children in a religion's organisation. The educator has been working with children and has good understanding of their developmental stages, characteristics and the relevant music various activities.

\section{She stated below that:}

'I have been teaching in the children department of my church before proceeding for teacher training. I understand their characteristics and their developmental milestone, and I know that the major channel of teaching them is through songs, hence using music to teach when I started my teaching career at the ECCE section is not a problem.' (A female ECCE educator, 44 years old)
For this participant, she gained her understanding from her family and motherhood roles to her children. See her response below:

'I love music, am from a music family and a mother, I have good understanding in using music to lure children to sleep. I have been turning words into music to teach my own children. Hence is not difficult for me to know the different music to use for the learner. I have different music to teach them communication vocabularies, two letters word, sounds, learning how to read and how to speak.' (A female ECCE educator, 40 years old)

Another participant connected her understanding and ability to use music-based pedagogy with her exploration of different children's music channels online. Below is her voice:

'I cannot sing. I do not have a singing voice, and am struggling and get embarrassed at times in front of the children. Thus, I committed myself to watching videos and singing at home or while driving to improve my skills. I browse the Internet to learn various songs that I can use to teach learners and currently am better and can use music to teach.' (A female ECCE educator, 30 years old)

Findings from the analyses of the responses of the participants during the interview as stated above show that the ECCE educators in the context of this study have understanding on the use of music to teach the ECCE learners' language and communication skills. They ascribed their sources of understanding to the formal training received, engagement in religious activities, motherhood role and support from online children music.

\section{Theme 4: Barriers to employing music-based pedagogies in the early childhood care and education classroom}

The participants stated that even though music was effective in supporting their learners' acquisition of relevant skills, three primary barriers prevented them from effectively employing music-based pedagogies in the classroom: their lack of sufficient training in music-based pedagogy, the lack of musical resources and the non-inclusion of music in the CAPS document. The participant below highlighted her lack of sufficient training in music-based pedagogy as a challenge for her to effectively use it in the classroom. She felt that teaching music for only a semester during the teacher training is not enough. Below is her comment:

'I attended University of South Africa (UNISA) and not much was done in music. We took a module for one semester and I felt that is not enough to fully train us to use music to teach. Although, I came from a music loving family but still need formal training. When I started this teaching career in ECCE, it was not easy initially. However, I have developed my skills by listening to children's music CDs.' (A female ECCE educator, 40 years old)

The omission of formal music-based pedagogy in the CAPS was identified as a barrier by the following participant:

'The big challenge is that as important as music is to the children, there is no music in the CAPS document. So, there is a need for 
the curriculum designers to specifically consider music so that more time will be given to it. There is only creative arts, but we use music to teach different skills and content, such as numeracy, rhymes, and language development. I think music is more relevant than any other subject for these children at this age.' (A female ECCE center's principal and educator, 53 years old)

The lack of musical resources in the classroom was pointed out as another challenge. The participants stated that using music-based pedagogies requires at least simple percussion instruments to accompany the songs, especially when teaching sound, pitch and stress as a basis for phonics in language. They complained of a lack of simple musical resources in the ECCE centres, as expressed by the following participant:

'The big challenge we have in this school is not just that we the teachers are not very sound in music, but there are not enough musical instruments. Teaching the children, the rudiments of language and communication skills demands a huge effort from the educators. [...] The major challenge the children face is in the area of reading to comprehend, and music is helpful, but we need to include the musical instruments specially to teach English sounds. I wish the Department of Education would come to our aid and support the school by providing musical instruments.' (A female ECCE center's principal and educator, 53 years old)

Data from the study showed that the ECCE educators from these centres acknowledged music as the best medium for impacting skills to the children. However, there are challenges hampering their effective use of music.

\section{Theme 5: Observation on the early childhood care and education educators' understanding of the use of music in the classroom}

The observation was carried out in the classroom and outside the classroom to examine how the educators carry out their teaching activities with the learners. I sang along with them and assisted the teacher to organise them. In this very class, the teacher has various instruments which she shared amongst the children, the song was to teach words with stress, and when the teacher reaches the point to stress, she signalled them and most of them use the percussion instruments they are playing to show the sign whilst watching the teacher but about two or three of the children were struggling with the teaching style, especially the new pupils. The teacher of this class was musically inclined and had good understanding of aligning the songs with the contents.

The next observation was carried out at the second centres, two classes of children aged between three and four were combined. The participants in charge of this class have partial knowledge of music and sorely depend on a series of songs downloaded from the internet to support the children to learn communication. The educator faced me and said that:

'Aunty as you can see am struggling with the use of music, am not very sound in music but trying to upgrade myself through internet.' (A female ECCE educator, and 30 years old)

\section{Theme 6: Observation on the various musical rhymes used, classroom atmosphere and children's response}

In the two centres, a series of themes were lined up to be taught to the children, themes such as two letter words, listening skills, learning about animals in the water and on the land, speech development and other themes. Songs and rhymes communicate and show appreciation, greetings and courtesy. There is other music to communicate self-confidence into them. There are songs to teach alphabets, and songs to teach phonics, sounds in language, songs to teach different colours, action songs were all used in the class to help the children to learn. The songs are of different forms, there were call and response songs, elementary instrumental music to support them to learn sound and pitch, short composition and songs that accompany stories. The educators have few contents that they teach the children in the traditional ways, but when the teacher shifted to music, the children shouted and screamed for joy. The fatigue and the sleeping children will suddenly pick up and join in the singing:

'When it comes to singing the children are awake, enthusiastic and lively in the classroom.' (A female ECCE educator, 40 years old)

I witnessed this during the observation exercises, the children actively participated in the learning activities.

\section{Discussion of result}

In South Africa, most ECCE teachers receive at least some training in music and thus have some level of efficacy in using music-based pedagogies to teach their learners. All South African teacher training universities offer creative arts as part of the Life Skills curriculum in pre-service teacher education programmes; however, creative arts is usually taught within a single semester, and music is only one of the four components - the other three being dance, drama and visual arts. Data from this study revealed that most ECCE teachers have only a very basic knowledge of how to use music-based pedagogies in the classroom.

\section{Theme 1: The nature of early childhood care and education educators' training}

Findings from this study revealed that the ECCE educators understand the use of music to teach the learners because of the various musical training received during their pre-service teacher program. Although the training received varied from one participant to the other, some received training in theory of music, instrumental music and were taught how to construct some musical instruments and music compositions. Two out of the six participants had sound music training from the university whilst three are products of the University of South Africa (UNISA), these latter claimed that they received partial musical training as part of the ECD programmes.

This finding is supported by Vygotsky (1997) of educators becoming MKO to be able to support learners to learn and 
Shulman (1987) ideas of the educators having sound comprehension of the content knowledge they intend to teach.

One of the participants stated that she received her music training when in high school. Those with sound musical training have less challenges in their use of music in the classroom. One of them added that music courses are made compulsory in the teacher training institutions across the country where she received her teacher training and that teaching practice in music was a mandatory exercise for pre-service teachers. She added that music courses are made compulsory in the teacher training institutions across the country and that teaching practice in music was a mandatory exercise for pre-service teachers. This finding is in congruence with the report of Barrett and Bond (2015) and Van Vuuren and Eurika (2018) that declared that a good number of teachers receive training in music and thus have self-efficacy to use music as a pedagogical medium to teach the learners. Additionally, some earlier researchers avow that virtually, all the South African universities offer creative arts subject in the pre-service teacher education programs, although the subject is usually taught within a single semester, but the pre-service teachers have the basic knowledge of the use of music in the classroom (cf. 5.3.2; Van Vuuren \& Eurika 2018). The finding also agrees with Vygotsky (1997) whose SocioCultural Theory emphasised that the teacher as MKO must have deeper understanding of the learners.

However, it is discovered from the study that majority of the participants do not have enough musical training that prepared them to teach music to the learners. This finding was confirmed by Atmore, Van Niekerk and Ashley-Cooper (2012) as well as Van Vuuren and Eurika (2018) as they mentioned that the music training received in schools is not enough to enhance the teachers effective use of music in the classroom. Additionally, the findings on teacher's understanding of using music as pedagogy in the classroom were supported by previous research studies, which reported that most of the ECCE educators have limited musical skills because of inadequate training, as $80 \%$ of them confessed to having difficulty in composing and using appropriate songs and rhymes for all the recommended ECCE contents (Almutairi \& Shukri 2016; Beukes 2016). The finding is not in line with Vygotsky (1997) and Shulman (1987) ideas of teachers as MKOs, who are expected to have sound content knowledge to support the learners to learn.

\section{Theme 2: Communication skills in early childhood care and education curriculum}

Communication is one of the six learning areas designed for Early Childhood Care and Education (ECCE) by the NCF. It has been indicated in the document that effective communication promotes healthy lifestyle, a strong sense of uniqueness and socialisation, development of strong mathematical concepts, acquisition of creative skills and knowledge of exploration of the world (Department of Basic Education 2015). Furthermore, various approaches of communicating through music in ECCE are clearly specified which include 'dance, music, art, pictures, singing, body movement, and creative play' (NCF 2015:41). The ECCE educators and caregivers are admonished to speak, sing, read to and listen to young children to support them as they learn communication skills (speaking and listening), and later learn reading and writing. However, it was pointed out in this study that communication skills were not taught to children aged between three and four, the participants claimed that the children aged between three and four are too young to learn communication skills. This idea is in contradiction with the NCF document. The implication of this is that the current challenges of inability to communicate some of the South African learners will continue to linger. The study is arguing and proposing that the teaching of communication skills using a variety of music should be enforced in ECCE centres.

\section{Theme 3: Early childhood care and education educators' understanding of using music-based pedagogy to teach communication skills}

Data showed that the ECCE educators understood the use of music-based pedagogies in the classroom as a result of basic musical training received during their pre-service teacher training. The participants were aware of their learners' developmental stage, and that their learners' acquisition of communication skills could be improved by implementing music-based pedagogies in the classroom, as these are the most appropriate teaching and learning strategies for ECCE learners. The finding refuted the report of Welch and Henley (2014), who disclosed that ECCE educators lack the knowledge required to implement musicbased pedagogy to teach communication skills. Some had received training in the theory of music and had been taught how to construct basic musical instruments and create simple compositions, whilst others received only brief training. A participant response revealed that she is conversant with the developmental stages of children through her motherhood experiences and understood that using music would support their learning. Amongst the teaching strategies, music is found to be relevant and effective that can be employed as an implementation tool in the ECCE classroom.

\section{Theme 4: Barriers to employing music-based pedagogies in the early childhood care and education classroom}

Under this theme, data revealed that the participants had good understanding of music as the best pedagogical medium for the ECCE classroom. However, there were some restraints hampering their effectiveness in the use of music. The barriers to the effective implementation of music-based pedagogies in the ECCE phase were therefore revealed to be systemic. In addition to insufficient provision in the various pre-service teacher training curricula, the educators in this study identified a lack of musical resources and the non-inclusion of music in the CAPS curriculum as barriers to the effective use of music-based pedagogies. 
They expressed the need for the educational authorities to take practical steps to provide the necessary resources to enable them to implement music-based pedagogies more effectively, by providing instruments and by modifying the CAPS curriculum to create more intentional space for music-based pedagogies to teach a variety of skills. This finding is confirmed by Van Vuuren and Van Niekerk (2015), who observed that the Life Skills curriculum where music is included is overloaded, and that insufficient space is provided for educators to employ music-based pedagogies. Additionally, Almutairi and Shukri's (2016) finding that $80 \%$ of ECCE educators had difficulty in composing appropriate songs and rhymes for the recommended content. Furthermore, the findings correspond with AdamsOjugbele and Moletsane's (2019) conclusion that educators' qualifications and the level of efficiency in their specialisation determine their productivity and effectiveness in interacting with and imparting skills to their learners.

The study revealed that the educators have good understanding of music as the best pedagogical medium for teaching any skill in the ECCE classroom. However, some of them wish that they had received efficient music training during their teacher education. This is in accordance with the SCT that underpinned the study, which states that only interaction between learners and a MKO can yield desirable results (Vygotsky 1997). The ECCE educators need adequate, relevant training to be this $\mathrm{MKO}$, in order to scaffold the learners' knowledge and skills using musical activities to improve the learners' communication skills.

\section{Theme 5: Findings from observation exercise on the early childhood care and education understanding of music-based pedagogy}

My observation exercise on the participants' classroom activities on how they use music to teach language and communication skills revealed most of the educators' struggle on aligning the relevant music with the various learning activities. The way in which the contents were communicated to the children through music, the children's responses and participation, the non-verbal expression during the singing activities, the duration of time spent before the learners grasp the learning objectives is different from one classroom to the other. The level of musical understanding and musical training received, and the musical experiences affect the level and their ability on the effective use of music in the classroom. The few educators who had sound training in music performed better in the use of various music to teach in the classroom. The finding from observation congruent with Weber et al. (2018) observed that a pre-requisite for effective teaching is adequate teacher training and professionalism. Additionally, Knight and Rabon (2017) added that because ECCE learners lack the ability to communicate eloquently, studying them through a developmental lens helps educators to understand their needs and how they might best help them to learn effectively.

\section{Theme 6: Observation on the various musical rhymes used, classroom atmosphere and children's response}

In the two centres, a series of themes were lined up to be taught to the children, themes such as two letter words, listening skills, learning about animals in the water and on the land, speech development and other themes. Songs and rhymes communicate and show appreciation, greetings and courtesy. There is other music to communicate self-confidence into them. There are songs to teach alphabets, and songs to teach phonics, sounds in language, songs to teach different colours, action songs were all used in the class to help learn the children. The songs are of different forms, there were call and response songs, choral songs, elementary instrumental music to support them to learn sound and pitch, short composition and songs that accompany stories. All these songs facilitated children's learning of any skills. The findings from previous study buttress this point by mentioning choral songs as an effective means of scaffolding children to learn skills:

Choral singing may provide children with an enjoyable experience that facilitates scaffolding by the more capable children in a Vygotsky paradigm. (Walton, Canaday \& Dixon 2014:69)

The themes taught by the teachers were divided into two sections, the first part was contents to teach speech development and the second part was general contents contained in the timetable that are meant to teach general skills. Additionally, the songs were performed on two major formations which include circle and line formation, and the children were arranged based on the theme to teach and the type of songs to use. In using the songs to teach vocabularies, sounds, learning of two letter words to aid the children's speech development, they were made to sit in a circle formation with their instruments whilst the teacher was in the centre with the contents to be learned written in small cards.

The use of music in the classroom increases the learners' interest and enthusiasm to learn. This finding was supported by Sayakhan and Bradley (2019) as they declare that rhythm in some of the rhymes makes the classroom lively and interested, as children sing and chant with clapping of hands.

\section{Implications}

The findings may have implications for ECCE policy planners, curriculum designers and implementers and higher education institutions that train pre-service ECCE educators in South Africa. The study confirmed that employing musicbased pedagogies to teach ECCE learners communication skills facilitates and enhances their acquisition of these skills, and promotes more sustainable learning than traditional ways of teaching. Policy makers should therefore put in place a well-structured plan that accommodates content that is relevant and beneficial to the learners' needs, and in particular should promote the use of music-based pedagogies to teach 
communication skills. Music should be included as an independent subject in the CAPS document.

Pre-service teachers' programmes must teach ECCE educators multiple pedagogies for inclusive classrooms, and pedagogies that suit the children's developmental stage and nature. Teacher-training institutions should encourage the acquisition of practical musical skills, and avoid providing only theoretical musical knowledge. The pre-service teachers' curriculum needs to be reviewed and revised to extend their learning of music pedagogy beyond just one semester. Professional development intervention programmes would also improve the music-based pedagogies of in-service teachers who were initially undertrained.

Finally, ECCE centres need to be provided with the necessary practical resources to enable educators and learners to engage in music-based teaching and learning activities. Addressing these issues will strengthen the ECCE curriculum and the educators' ability to engage in the appropriate pedagogical strategies for this age group, thereby aiding the children acquisition of communication skills at a young age.

\section{Recommendations for further research}

This study was a qualitative case study of a small sample of only six ECCE educators from two urban centres; thus, more elaborate and in-depth research could be conducted on more centres and larger or different populations, especially educators from rural settings who deal with vulnerable children. There is a need for research on the perspective of ECCE learners in relation to how musical pedagogies aid their learning of communication skills. This could be further extended to reception year (Grade R) learners. There is also a need for further research on how ECCE educators in South Africa are following the NCF document by using musical pedagogies to support ECCE learners to acquire communication skills, as recommended in the documents. Finally, this study did not examine the effect of the children's cultural background on their acquisition of communication skills through music. Whilst the learners in this study spoke a range of home languages, the ECCE educators used English as the language of learning and teaching for all the learners. Thus, there is a need for study that examines the influence of ECCE learners' family and the cultural background on their acquisition of communications skills using music. The further studies could focus on questions such as: How does the use of music as a pedagogical medium aid the children's language development? What is the effect of the children's cultural background on their acquisition of communication skills through music? How are the ECCE educators following the NCF document by using musical pedagogies to support ECCE learners to acquire communication skills? What types of music do they use in the ECCE classroom to support the children to learn communication skills? Addressing the questions may go a long way in proffering the best teaching strategies that support children's acquisition of communication skills, thereby ameliorating the current issues on reading difficulty of children.

\section{Conclusion}

In South Africa, a speedy intervention to improve learners' communication skills has become imperative. This study confirmed that the ECCE educators have some levels of understanding of music-based pedagogies to teach communication skills to the learners. The finding further revealed that music-based pedagogy has a positive effect on ECCE learners' acquisition of these skills. The findings emphasise that using music-based pedagogies at this foundational level of education is important for ECCE learners' effective acquisition of communication skills, and that all barriers to effective implementation should be removed.

\section{Acknowledgements}

The authors acknowledge the University of KwaZulu-Natal and the University of Zulu Land.

\section{Competing interests}

The authors have declared that no competing interest exists.

\section{Authors' contributions}

The first author wrote the article whilst the second author proofread and effect the necessary corrections.

\section{Ethical considerations}

Ethical clearance document from the University of KwaZuluNatal Research Ethics Committee was acquired before proceeding to the research participants. Moreover, the participants were assured of their confidentiality and freedom to withdraw at any time they felt not comfortable to continue with the study. Morley et al. (2019) as well as Floridi and Cowls (2019) stated the three ethical principles that a researcher needs to follow in conducting a research. These are autonomy, which implies that the researcher obtains the consent of every person who will participate in the study; non-maleficence ensuring the confidentiality of the participants' information and personality and beneficence suggest the research benefit the participants had directly or indirectly. These are duly adhered to.

Thus, all ethical measures specified by the University of KwaZulu-Natal Research Ethics Committee were strictly obeyed, including the issuing of an ethical clearance certificate (HSS/1940/180D).

\section{Funding information}

This research received no specific grant from any funding agency in the public, commercial or not-for-profit sectors.

\section{Data availability}

Data sharing is not applicable to this article as no new data were created or analysed in this study. 


\section{Disclaimer}

The views and opinions expressed in this article are those of the authors and do not necessarily reflect the official policy or position of any affiliated agency of the authors.

\section{References}

Adams-Ojugbele, R.O. \& Moletsane, R., 2019, 'Towards quality early childhood development for refugee children: An exploratory study of a grade $\mathrm{R}$ class in Durban childcare centre', South African Journal of Childhood Education 9(1), 8. https://doi.org/10.4102/sajce.v9i1.616

Almutairi, M. \& Shukri, N., 2016, 'Using songs in teaching oral skills to young learners: Teachers' views and attitudes', International Journal of Linguistics 8(6), 133-153. https://doi.org/10.5296/ijl.v8i6.10464

Alterator, S. \& Deed, C., 2013, 'Teacher adaptation to open learning spaces', Issues in Educational Research 23(3), 315, viewed 11 June 2021, from http://www.iier.org. au/iier23/alterator.html.

Atmore, E., Van Niekerk, L.J. \& Ashley-Cooper, M., 2012, 'Challenges facing the early childhood development sector in South Africa', South African Journal of Childhood Education 2(1), 120-139. https://doi.org/10.4102/sajce.v2i1.25

Barrett, M. \& Bond, N., 2015, 'Connecting through music: The contribution of a music programme to fostering positive youth development', Research Studies in Music Education 37(1), 37-54. https://doi.org/10.1177/1321103X14560320

Ba'th, F. \& Mychailyszyn, M.P., 2017, 'The power of musical learning: A pilot study of whether private music lessons can decrease parental stress and disruptive behaviour in children', Mental Health Family Medicine 14(1), 642-651.

Bertram, C. \& Christiansen, I., 2014, Understanding research: An introduction to reading research, Van Schaik Publishers, Pretoria.

Beukes, D.B., 2016, 'Creative arts in pre-service teacher education at South African universities: A case study', Unpublished doctoral thesis, University of Pretoria, viewed 11 June 2021, from https://repository.up.ac.za/bitstream/handle/2263/ 60405/Beukes_Creative_2017.pd f?sequence=1\&isAllowed=y.

Bolduc, J. \& Evrard, M., 2017, 'Music education from birth to five: An examination of early childhood educators' music teaching practices', Research and Issues in Music Education 13(1), 3

Brandt, A., Gebrian, M. \& Slevc, L.R., 2012, 'Music and early language acquisition', Frontiers in Psychology 3, a327. https://doi.org/10.3389/fpsyg.2012.00327

Britto, P.R., Lye, S.J., Proulx, K., Yousafzai, A.K., Matthews, S.G., Vaivada, T. et al., 2017, 'Nurturing care: Promoting early childhood development', The Lancet 389(1), 91-102. https://doi.org/10.1016/S0140-6736(16)31390-3

Bronfenbrenner, U., 1992, 'Ecological systems theory', in R. Vasta (ed.), Six theories of child development: Revised formulations and current issues, pp. 187-249, Jessica child development: Revised
Kingsley Publishers, London.

Cloete, E. \& Delport, A., 2015, 'Music education in the grade R classroom: How three teachers learned in a participatory action inquiry', South African Journal of Childhood Education 5(1), 1-24. https://doi.org/10.4102/sajce.v5i1.351

Cumming, T., 2017, 'Early childhood educators' well-being: An updated review of the literature', Early Childhood Education Journal 45(5), 583-593. https://doi. org/10.1007/s10643-016-0818-6

Dalton, E.M., Mckenzie, J.A. \& Kahonde, C., 2012, 'The implementation of inclusive education in South Africa: Reflections arising from a workshop for teachers and therapists to introduce universal design for learning', African Journal of Disability 1(1), 1-7. https://doi.org/10.4102/ajod.v1i1.13

Department of Basic Education (DBE), 2015, The South African national curriculum framework for children from birth to four, Department of Basic Education, Pretoria.

De Vries, P., 2013, 'Generalist teachers' self-efficacy in primary school music teaching', Music Education Research 15(4), 375-391. https://doi.org/10.1080/14613808.20 Music Educati
13.829427

Eerola, P. \& Eerola, T., 2014, 'Extended music education enhances the quality of school life', Music Education Research 16(1), 88-104. https://doi.org/10.1080/14613808. 2013.829428

Fernández, M., Wegerif, R., Mercer, N. \& Rojas-Drummond, S., 2013, 'Re-conceptualizing "scaffolding" and the zone of proximal development in the context of symmetrica collaborative learning', Journal of Classroom Interaction 50(1), 54-72.

Floridi, L. \& Cowls, J., 2019, 'A unified framework of five principles for Al in society', Harvard Data Science Review 1(1), 1-15. https://doi org/10.1162/99608f92.8cd550d1

Ford, A.L., Elmquist, M., Merbler, A.M., Kriese, A., Will, K.K. \& McConnell, S.R., 2020, 'Toward an ecobehavioral model of early language development', Early Childhood Research Quarterly 50, 246-258. https://doi.org/10.1016/j.ecresq.2018.11.004

Gillespie, C.W. \& Glider, K.R., 2010, 'Preschool teachers' use of music to scaffold children's learning and behaviour', Early Child Development and Care 180(6), 799-808. https://doi.org/10.1080/03004430802396530

Halberda, J. \& Feigenson, L., 2008, 'Developmental change in the acuity of the "number sense": The approximate number system in 3-, 4-, 5-, and 6-year-olds and adults' Developmental Psychology 44(5), 1457-1465. https://doi.org/10.1037/a0012682

Hancock, D.R. \& Wright, S.W., 2018, 'Enhancing early childhood development through arts integration in economically disadvantaged learning environments', The Urban Review 50(3), 430-446. https://doi.org/10.1007/s11256-017-0440-y

Hansen, D., Bernstorf, E. \& Stuber, G.M., 2014, The music and literacy connection, 2nd edn., Rowman \& Littlefield, Lanham, MD.
Haslip, M.J. \& Gullo, D.F., 2018, 'The changing landscape of early childhood education: Implications for policy and practice', Early Childhood Education Journal 46(3), 249-264. https://doi.org/10.1007/s10643-017-0865-7

Hawkins, S., 2016, 'Great Scott!', in S. Hawkins (ed.), Critical musicological reflections: Essays in honour of Derek B. Scott, pp. 1-20, Routledge, London.

Herrera, L., Hernández-Candelas, M., Lorenzo, O. \& Ropp, C., 2014, 'Music training influence on cognitive and language development in 3 to 4 year-old children', Revisto de Psicodidáctica 19(2), 367-386. https://doi.org/10.1387/RevPsicodidact.9761

Horng, J.S., Hong, J.C., ChanLin, L.J., Chang, S.H. \& Chu, H.C., 2005, 'Creative teachers and creative teaching strategies', International Journal of Consumer Studies 29(4), 352-358. https://doi.org/10.1111/j.1470-6431.2005.00445.x

Jäncke, L., 2012, 'The relationship between music and language', Frontiers in Psychology 3, 123. https://doi.org/10.3389/fpsyg.2012.00123

Kamalodeen, V.J., Figaro-Henry, S., Ramsawak-Jodha, N. \& Dedovets, Z., 2017, 'The development of teacher ICT competence and confidence in using web 2.0 tools in a STEM professional development initiative in Trinidad', The Caribbean Teaching Scholar 7(1), 25-46.

Khaghaninejad, M.S., Motlagh, H.S. \& Chamacham, R., 2016, 'How does Mozart's music affect the reading comprehension of Iranian EFL learners of both genders?', International Journal of Humanities and Cultural Studies (IJHCS), Special issue May 2016, viewed 11 June 2021, from https://www.ijhcs.com/index.php/ijhcs/article/ view/730.

Knight, A. \& Rabon, P., 2017, 'Music for speech and language development in early childhood populations', Music Therapy Perspectives 35(2), 124-130. https://doi. org $/ 10.1093 / \mathrm{mtp} / \mathrm{mix} 014$

Linnavalli, T., Putkinen, V., Lipsanen, J., Huotilainen, M. \& Tervaniemi, M., 2018, 'Music playschool enhances children's linguistic skills', Scientific Reports 8(1), 1-10. https://doi.org/10.1038/s41598-018-27126-5

McIntire, J.M., 2007, 'Developing literacy through music', Teaching Music 15(1), 44-48.

McLeod, S.A., 2018, 'Lev Vygotsky', in Simply psychology, viewed 11 June 2021, from https://www.simplypsychology.org/vygotsky.html.

Miles, M.B. \& Huberman, A.M., 1994, Qualitative data analysis: An expanded sourcebook, 2nd edn., Sage, California.

Modisaotsile, B.M., 2012, The failing standard of basic education in South Africa. Policy brief, 72, pp. 1-7, viewed 11 June 2021, from https://www.purpletod.co.za/ docs/FAILING\%20STANDARDS.pdf

Mohangi, K., Krog, S., Stephens, O. \& Nel, N., 2016, 'Contextual challenges in early iteracy teaching and learning in grade R rural schools in South Africa', Per Linguam 32(1), 71-87. https://doi.org/10.5785/32-1-646

Morley, J., Floridi, L., Kinsey, L. \& Elhalal, A., 2020, 'From what to how: An initial review of publicly available Al ethics tools, methods and research to translate principles into practices', Science and Engineering Ethics 26(4), 2141-2168. https://doi. org/10.1007/s11948-019-00165-5

Morley, J., Floridi, L, Kinsey, L. \& Elhalal, A, 2019, 'From what to how. An overview of Al ethics tools, methods and research to translate principles into practices', viewed from arXiv preprint arXiv: 1905.06876.

Nel, N., Krog, S., Mohangi, K., Muller, H. \& Stephens, O., 2016, 'Research partnership between South Africa and China: Emergent literacy teaching and learning in early childhood education in South Africa', Per Linguam: A Journal of Language Learning 32(1), 102-122. https://doi.org/10.5785/32-1-647

Niland, A., 2009, 'The power of musical play: The value of play-based, child-centered curriculum in early childhood music education', General Music Today 23(1), 17-21. https://doi.org/10.1177/1048371309335625

Niland, A. \& Holland, J., 2019, 'Journeys towards empowerment: Educators sharing their musical cultural identities with children', International Journal of Music in Early Childhood 14(1), 71-88. https://doi.org/10.1386/ijmec.14.1.71_1

Parsad, B. \& Spiegelman, M., 2012, Arts education in public elementary and secondary schools: 1999-2000 and 2009-10, Report NCES 2012-2014, viewed 11 June 2021, from http://nces.ed.gov/pubs2012/2012014rev.pdf.

Piaget, J., 1952, The origins of intelligence in children, W.W. Norton \& Co. New York, NY.

Roberts, M.Y., Kaiser, A.P., Wolfe, C.E., Bryant, J.D. \& Spidalieri, A.M., 2014, 'Effects of the teach-model-coach-review instructional approach on caregiver use of language support strategies and children's expressive language skills', Journal of Speech, Language, and Hearing Research 57(5), 1851-1869. https://doi org/10.1044/2014_JSLHR-L-13-0113

Rule, P. \& Land, S., 2017, 'Finding the plot in South African reading education', Reading \& Writing 8(1), a121. https://doi.org/10.4102/rw.v8i1.121

Ryan, R.A., 2020, 'Integrating the musical, the natural, and the improvised: David Rothenberg and multispecies musicking', Jazz Education in Research and Practice 1(1), 167-184. https://doi.org/10.2979/jazzeducrese.1.1.12

Sampa, F.K., Ojanen, E., Westerholm, J., Ketonen, R. \& Lyytinen, H., 2018, 'Literacy programs efficacy for developing children's early reading skills in familiar language in Zambia', Journal of Psychology in Africa 28(2), 128-135. https://doi.org/10.1080 /14330237.2018.1435050

Sayakhan, N. \& Bradley, D., 2019, 'Nursery rhymes as a vehicle for teaching English as a foreign language', Journal of University of Raparin 6(1), 44-55. https://doi. org/10.26750/vol(6).no(1).paper4

Shabani, K., 2016, 'Implications of Vygotsky's sociocultural theory for second language (L2) assessment', Cogent Education 3(1), 1-16. https://doi.org/10.1080/233118 6X.2016.1242459

Shulman, L., 1987, 'Knowledge and teaching: Foundations of the new reform' Harvard Educational Review 57(1), 1-23. https://doi.org/10.17763/ haer.57.1.j463w79r56455411 
Teddlie, C. \& Yu, F., 2007, 'Mixed methods sampling: A typology with examples', Journal of Mixed Methods Research 1(1), 77-100. https://doi.org/10.1177/1558689806292430

United Nations Children's Fund (UNICEF), 2014, Early childhood development: A statistical snapshot, viewed 11 June 2021, from https://www.unicef.org/ earlychildhood/files/ECD_Brochure_FINAL_LR.pdf.

Vandenbroeck, M. \& Lazzari, A., 2014, 'Accessibility of early childhood education and care: A state of affairs', European Early Childhood Education Research Journal 22(3), 327-335. https://doi.org/10.1080/1350293X.2014.912895

Van Vuuren, E.J. \& Van Niekerk, C., 2015, 'Music in the life skills classroom', British Journal of Music Education 32(3), 273-289. https://doi.org/10.1017/ Journal of Music
S0265051715000340

Van Vuuren, J. \& Eurika, N., 2018, 'Arts across the curriculum as a pedagogy for primary school teachers', South African Journal of Childhood Education 8(1), 1-10.

Vygotsky, L.S., 1997, The collected works of LS Vygotsky: Problems of the theory and history of psychology, vol. 3, Springer Science \& Business Media, New York.

Walker, S.P., Wachs, T.D., Grantham-McGregor, S., Black, M.M., Nelson, C.A., Huffman, S.L. et al., 2011, 'Inequality in early childhood: Risk and protective factors for early child development', The Lancet 378(9799), 1325-1338. https://doi.org/10.1016/ S0140-6736(11)60555-2
Walton, P.D., Canaday, M. \& Dixon, A., 2014, 'Using songs and movement to teach reading to aboriginal children', Canadian Council on Learning 16(3), 54-77. https://doi.org/10.20360/G2K88J

Weber, K.E., Gold, B., Prilop, C.N. \& Kleinknecht, M., 2018, 'Promoting pre-service teachers' professional vision of classroom management during practical school training: Effects of a structured online-and video-based self-reflection and feedback intervention', Teaching and Teacher Education 76, 39-49. https://doi org/10.1016/j.tate.2018.08.008

Welch, G.F. \& Henley, J., 2014, 'Addressing the challenges of teaching music by generalist primary school teachers', Revista da ABEM 22(32), 12-38.

Whitcomb, R., 2013, 'Teaching improvisation in elementary general music: Facing fears and fostering creativity', Music Educators Journal 99(3), 43-51. https://doi. org $/ 10.1177 / 0027432112467648$

Wolfe, S. \& Flewitt, R., 2010, 'New technologies, new multimodal literacy practices and young children's metacognitive development', Cambridge Journal of Education 40(4), 387-399. https://doi.org/10.1080/0305764X.2010.526589

Young, S., 2016, 'Early childhood music education research: An overview', Research Studies in Music Education 38(1), 9-21. https://doi.org/10.1177/1321103 X16640106 